\title{
A ritmo de bombeo: teoría y métodos para el estudio antropológico en un espacio de venopunción asistida de Barcelona
}

\author{
Rafa Clua ${ }^{1}$
}

resumen En este artículo se desarrolla, desde un plano teórico-metodológico, un estudio realizado en el Espacio de Venopunción Asistida (EVA) del Servei d'Atenció i Prevenció Socio Sanitària (SAPS) de Creu Roja de Barcelona. Un EVA es un lugar para consumir drogas por vía intravenosa bajo la supervisión de un profesional. La investigación se contextualizó desde la perspectiva histórica de la intervención en drogas en España, profundizando en el fenómeno de las salas de consumo higiénico (SCH), bajo el enfoque del interaccionismo simbólico y las teorías sobre la exclusión social actuales. Se realizó el trabajo de campo utilizando diferentes técnicas de recogida de información y análisis, trazándose conclusiones y propuestas para mejorar la intervención en drogas desde las SCHs. Esta investigación se sitúa como un nuevo enfoque para el estudio de las $\mathrm{SCH}$, complementando los resultados obtenidos desde otras perspectivas.

palabras clave Salas de consumo higiénico. Interaccionismo simbólico. Drogas. Exclusión social. Métodos de investigación.

"Encontré la vena en seguida. Un chorro de sangre entró en la jeringuilla durante unos instantes, intenso y sólido como una cuerda roja. Apreté el émbolo con el pulgar, notando que la droga se extendia por mis venas para alimentar a un millón de células hambrientas de droga y para proporcionar fuerza y vivacidad a cada nervio y a cada músculo" (William Burroughs, Almuerzo al desnudo)

"Los refugios son numerosos, la salvación es una sola, pero las probabilidades de salvación tornan ser tantas como los refugios." (Franz Kafka, Consideraciones acerca del pecado)

\section{Introducción}

El fenómeno del uso de las drogas y sus efectos - experienciales, sociales, sanitarios, jurídicos y políticos, entre otros - ha sido de gran interés para la antropología en España desde finales de los años 70, investigándose en diferentes contextos de su marco geográfico. Desde entonces, esta disciplina ha vivido los cambios de los paradigmas de intervención en drogodependencias, en muchos casos, aportando un análisis tanto teórico como práctico para paliar los efectos negativos del consumo de las drogas. En la actualidad, el paradigma emergente es el de las políticas en reducción de daños, políticas de carácter pragmático que tienen el objetivo de minimizar los riesgos y daños del consumo de drogas. Entre sus intervenciones se encuentran las $\mathrm{SCH}$; la presente investigación se desarrolla en uno de estos espacios.

En este estudio, realizado entre febrero y junio de 2010, nos situamos en el EVA del 
256 | RAFA CluA

SAPS de Creu Roja de Barcelona, centro destinado a consumidores de drogas y trabajadores/as del sexo en situación de exclusión social que interviene desde abril de 1993. Se ubica en la primera planta de un complejo sanitario del barrio del Raval y, en la actualidad, ofrece una atención biopsicosocial, educativa y jurídica por un equipo multidisciplinar compuesto de enfermeros, educadores, trabajadora social, médico, psicóloga, abogada, administrativa y coordinadora, de lunes a viernes de 19:30 a 1h. de la noche. Los diferentes espacios del SAPS cumplen funciones específicas: programa de intercambio de jeringuillas (dispensación de jeringuillas y parafernalias para el consumo intravenoso, y material para el consumo por vía pulmonar), enfermería/despacho de entrevistas (asistencia sanitaria e intervenciones psicosociales para mejorar la salud y la situación social del usuario), Club (zona de "café-calor" con espacio para la alimentación, duchas y ropero, y para realizar talleres e intervenciones educativas) y el EVA. Fuera de los límites del centro, se realiza la recogida de jeringuillas desechadas en la comunidad (programa Reco.Je). El EVA funciona desde octubre 2003 y, en la actualidad, ofrece dos plazas para el consumo inyectado de heroína y/o cocaína. Desde este espacio se facilita material estéril para la preparación y consumo de drogas, garantizándose condiciones higiénicas y asistencia en caso de sobredosis. En este espacio suelen intervenir enfermeros con el apoyo de educadores sociales.

La información de este artículo se extrae de la investigación "A ritmo de bombeo. Usos, motivaciones y cambios de los usuarios del espacio de venopuncion asistida (EVA) del Servei d' Atencio i Prevenció Socio Sanitària (SAPS) de Creu Roja de Barcelona y el rol de sus profesionales" (Clua, 2010) realizada dentro del marco del "Màster Oficial d'Investigació etnogràfica, teoria antropològica i relacions interculturals" de la Universidad Autónoma de Barcelona y dirigida por Aurelio Díaz. Su título responde, en un sentido metafórico, a los efectos de la intervención en drogodependencias. El "bombeo" es una práctica que realizan los consumidores de drogas por vía intravenosa, que consiste en absorber e introducir reiteradamente la sangre una vez inyectada la sustancia; es un acto que sugiere placer y dolor. La intervención en drogodependencias se mueve a ese ritmo, en ocasiones placentera y en otras, dolorosa, a veces eficaz y en otros casos, insatisfactoria. Aunque se pretende cubrir todas las necesidades del consumidor en riesgo de exclusión social, siguen quedando huecos difíciles de llenar. La intervención en drogas es como "bombearse", es un "mito". Ni el "bombeo" producirá más placer en el consumo inyectado, ni las innovaciones en el campo de la intervención en drogas, serán capaces de solucionar el "problema”. Quizás nos encontremos ante una especie de "leitmotiv", donde la secuencia de la marginalidad se repite continuadamente, impidiendo avanzar. Mientras, seguimos enfrentándonos a nuevos desafíos.

Los objetivos generales de la investigación fueron: a) Conocer los usos, motivaciones y cambios de los usuarios de drogas por vía parenteral que frecuentan el EVA del SAPS de Creu Roja de Barcelona, y b) Conocer el rol del profesional que interviene en el SAPS. Concretamente se quiso: a) Conocer el perfil de los usuarios que acuden al EVA: factores sociodemográficos, socioeconómicos, estado de salud y uso de drogas; b) Conocer por qué los usuarios han decidido utilizar el EVA y qué usos realizan; c) Conocer cuáles son las motivaciones de los usuarios al utilizar el EVA, es decir, si lo frecuentan para algo más que para inyectarse drogas; d) Conocer los cambios que experimentan los usuarios que acuden al EVA; e) Conocer el grado de satisfacción de los usuarios sobre la atención recibida; f) Conocer si lo que 
se le ofrece al usuario es suficiente para mejorar su calidad de vida. Tras el trabajo de campo, se obtuvieron resultados, aportando conclusiones y propuestas para replantear la intervención de los servicios de reducción de dańos, y en general, del campo de las drogodependencias.

En el presente artículo, profundizaremos en la teorización y en la metodología que se llevó a cabo a lo largo del estudio, además de una reflexión de porqué es necesario el enfoque antropológico para el estudio de las SCHs.

\section{Teoría antropológica en un EVA}

\section{1) Intervención en el ámbito de las drogas en España}

Los 80s: de la abstinencia al inicio del pragmatismo

Entre finales de los 70 y principios de los 80 , son cuatro los procesos que conducen al "problema droga" en España (Gamella, 1997): la rápida expansión de formas de alta intensidad de consumir drogas; una intensa alarma social e institucionalización para combatir el problema; una nueva economía, sumergida, dedicada a la producción y distribución de drogas; y el desarrollo de un problema de salud pública que conduce a una crisis sanitaria, que bajo la influencia de los mass media, fomentó la sensación de inseguridad ciudadana.

La heroína, sustancia ligada durante la década de los años 70 a un pequeño grupo contracultural, pasa a ser utilizada por los jóvenes de barrios marginales, surgiendo una nueva "identidad yonqui" (Usó, 1995, p. 330). Ante este "problema" se plantearon dos modelos de actuación interrelacionados: el modelo penal y el modelo médico (Magrí, 1997). Médicos y jueces aúnan fuerzas para encerrar o institucionalizar al entonces llamado toxicómano, estigmatizado con dos etiquetas: los jueces enviaban a los "delincuentes" a prisión para un tratamiento moral, y los médicos ofrecían tratamiento ambulatorio o enviaban a los "enfermos" a comunidades terapéuticas para realizar programas libres de drogas. Sólo existía una opción: "dejar la heroína” y fuera cual fuera el prototipo de consumidor (Funes y Romaní, 1985), no existía un abanico amplio de tratamientos, intervenciones, y/o estrategias para el abordaje de la problematización del consumo de drogas. Además, con el primer caso de VIH/ SIDA en 1981, se potenció considerablemente la estigmatización de los "yonquis", siendo rechazados por la sociedad y considerados como "grupo de riesgo" por las instituciones sanitarias, junto a prostitutas, homosexuales y otras personas de vida "insana” (Guasch, 1992).

Tras la alarma social, a finales de los 80, fue necesario buscar soluciones pragmáticas que se ajustaran a las necesidades de los usuarios. Se implantaron programas de mantenimiento con metadona (PMM) y programas de intercambio de jeringuillas (PIJ), cambiando el carácter de la intervención. Surge el modelo biopsicosocial, en el que "además del substrato biológico, se reconoce el papel del individuo y su entorno, tanto en los efectos experimentados a través de la substancia, como en el mantenimiento de una adicción" (Magrí, 1997, p. 223).

Los 90: del tratamiento a la reducción de daños

En los años 90, se produce la "alarma de la cocaína". Esta sustancia se asociaba a "consumidores de éxito" dentro de un contexto no marginal, de ocio y de uso ocasional (Díaz, 
Barruti, Doncel, 1992, p. 18), pero con la mala imagen que adoptó la heroína, los nuevos grupos juveniles darían paso al uso de otras drogas, entre ellas la cocaína (Usó, 1995, p. 351). Además, se potenciaría su uso entre los consumidores de tipo "heroinómano" y "exheroinómano" (Díaz, Barruti, Doncel, 1992). Los primeros, la usarían mezclada con heroína - bajo el nombre de "speedball" - para contrarrestar los efectos indeseables de la heroína. Los segundos, la usarían como vía de escape, ritualizada a modo de "fiesta". En muchos casos, tras un prolongado periodo de consumo compulsivo, aparecerían problemas sanitarios y sociales, y los centros de salud darían cobertura tanto a los consumidores "modernos" como a los "heroinómanos".

Durante esta década, se desarrollan programas más abiertos desde las "políticas de reducción de daños": estas dan prioridad al objetivo de disminuir los efectos negativos del uso de las drogas, experimentadas por individuos y comunidades, como alternativa a los enfoques basados en la abstinencia (O’Hare et al., 1995). Por otro lado, favorablemente, a mediados de los 90, aparecen los primeros tratamientos del VIH/SIDA, ofreciendo esperanzas y nuevas expectativas de vida a los usuarios de drogas, y a la población en general, infectada por el virus.

Se producirá un gran despliegue de los PMM y los PIJ en la ciudad de Barcelona y en Cataluña. En el caso de los PMM, como tratamiento de la heroína, son programas que trabajan a dos niveles: a nivel sanitario, mejorando la calidad de vida del consumidor, reduciéndose las muertes por sobredosis y de enfermedades infectocontagiosas (VIH y hepatitis), y a nivel social, disminuyendo la conflictividad social y los costes comunitarios (p.e.: ingresos en hospitales) (Gencat, 2002). Durante los años 80, la metadona fue una sustancia un tanto descontrolada, que se dispensaba desde clínicas privadas. Para mejorar su control, se dictó desde el Real
Decreto de 1990 unos criterios estrictos para su dispensación, otorgando la responsabilidad del tratamiento a centros específicos de atención en drogodependencias de la red pública. En el caso catalán, son los centros de atención y seguimiento a las drogodependencias (CAS). En Barcelona, bajo las propuestas del "Plà d'acció a les drogodependències 89-91" comienzan en 1991 los PMM en los CAS (Manzanera et al., 2000). Entre los años 1992 y 1994, se amplía la oferta asistencial de los CAS, implantándose en muchos distritos de Barcelona y municipios de Cataluña. La experiencia se diversificó con la llegada de la Olimpiadas del 92: se crea el primer programa piloto de PMM en prisión (prisión de hombres de Barcelona, La Modelo) y copiando el modelo holandés, se crearon dos unidades móviles de dispensación de metadona con el objetivo de dar cobertura a los usuarios con difícil acceso a los CAS: en 1992 en la ciudad de Barcelona, y en 1993, en la periferia de esta ciudad.

La diversificación y flexibilización de los PMM produjo la iniciación de muchos consumidores al programa, pero no cubriría las necesidades de muchos otros. El hecho de ser una sustancia por vía oral y no inyectada, eliminaba uno de los aspectos rituales más identificadores de una cierta "cultura yonqui" (Romaní, 2004, p. 184), además de imponerse por parte de los profesionales "determinados modelos de vida, previamente definidos como saludables" (Pallarés, 1995, p. 120). La metadona no sería una panacea, ni una opción válida para todos los consumidores de heroína.

Los PIJ, empiezan a implementarse en 1988 en la ciudad de Barcelona y en Cataluña. Estos programas proponen usar jeringuillas nuevas con el objetivo de reducir las enfermedades infectocontagiosas (VIH y hepatitis) y promover un acercamiento de los consumidores a los centros de salud. Al principio, eran programas de calle, dedicados a la recogida de jeringuillas 
desechadas en la vía pública. A partir de 1991, para dar más cobertura, se diversificaron en diferentes modalidades de PIJs (Romero et al., 2000): programas en locales y dispositivos fijos, programas en farmacias, máquinas dispensadoras/intercambiadoras, y en unidades móviles.

Tras establecerse los PMM en los CAS, y los primeros puntos de PIJ, nace una nueva modalidad de centros de acercamiento, ofreciendo servicios socio-sanitarios para dar cobertura a las necesidades básicas de los consumidores de drogas: los centros de reducción de daños (CRD). Por ejemplo, el SAPS de Creu Roja de Barcelona.

Nuevo milenio: de la reducción de daños a...

En el año 2001, continúan los PMM, los PIJ, los CRD, y se suman las SCHs, de las que hablaremos en el siguiente punto, y los programas de prescripción de heroína. Aunque existe un cambio de modelo, se continúan utilizando las mismas intervenciones que en los 80: conviven las instituciones totales (prisión, unidades hospitalarias, comunidades terapéuticas) con los programas ambulatorios (CAS y centros de salud).

Los PMM se diversificaron y aumentó el número de usuarios en programa. A finales de los 90 y principios del nuevo milenio, se inicia la dispensación en farmacias para usuarios estabilizados, y se comienza a hablar de los programas de "baja exigencia", que no persiguen la eliminación total del consumo de heroína u otras sustancias, sino una mejora en la calidad de vida de los consumidores. Por ejemplo, durante 2004, tras el desalojo del barrio de Can Tunis, se puso en marcha un programa de monodosis (ASPB, 2004) con el objetivo de dispensar metadona a dosis baja y acercar a los usuarios en situación marginal a la red asistencial.
Los PIJ aumentaron los puntos de dispensación en toda Cataluña y se instauraron en las prisiones. La primera experiencia en España fue en 1997 en el centro penitenciario (CP) de Basauri (País Vasco), seguida por la experiencia del CP Pamplona (Navarra) en 1998. Desde entonces, poco a poco se van implementando, aunque muy lentamente, por todas las prisiones del estado. En Cataluña, donde las competencias de prisiones están cedidas a esta comunidad autónoma, se tuvo que esperar al acuerdo del Parlament de Cataluña en octubre del 2002, para la implementación progresiva de los PIJ en todos los CPs catalanes. En mayo de 2003, se implementó el primer PIJ en CP Tarragona, y en 2006, el programa estaba en la totalidad de los CPs de Cataluña, excepto en el CP La Modelo de Barcelona, donde la oposición de los sindicatos tienen mayor fuerza que en otros CP de esta comunidad autónoma (Clua, 2008). Además, en las prisiones catalanas se implementaron los CAS; a finales de 2005, en la prisión de Brians 1 y a finales de 2007, en Brians 2.

Entre los ańos 2003-2004, se pusieron en marcha ensayos clínicos con heroína en las comunidades autónomas de Catalunya y Andalucía, persiguiendo mejorar la calidad de vida de aquellos usuarios de heroína que habían fracasado reiteradamente en otros programas. Entre 2003-2006, en el caso andaluz, se gestionó con equipos multidisciplinares que ofrecían en diferentes franjas horarias, 2 dosis de Diacetilmorfina (DAM) inyectada y una de metadona oral a los usuarios receptores del programa, obteniendo resultados positivos (Iraurgi, 2009, p. 209). En la actualidad, se mantiene una veintena de pacientes en tratamiento de uso compasivo, y se ha iniciado un nuevo ensayo. En 2004-2006, en Catalunya, el programa se inició en las unidades de drogodependencias de diferentes hospitales; está pendiente la presentación del informe de resultados (Id., Ibidem). 
260 RAFa Clua

\section{2) Las salas de consumo higiénico: una aproximación histórica y del contexto}

La primera experiencia oficial de $\mathrm{SCH}$ se sitúa en Berna (Suiza) en el año 1986, seguido de las experiencias de Frankfurt (Alemania), en 1994, y Rotterdam (Holanda), en 1996. Sus objetivos eran cerrar las escenas abiertas de consumo de drogas y dar atención a los consumidores de drogas en exclusión social. Se sumaron nuevas experiencias en estos países, y se prolongaron en otros de la comunidad europea (Luxemburgo, Noruega y Espańa), y en Australia y Canadá. En la actualidad está en proyección la apertura de nuevas $\mathrm{SCH}$ en Europa y Norteamérica (Hedrich, 2004).

En España, las SCHs existen en tres comunidades autónomas. Las dos primeras se instalaron en dos escenas abiertas de venta y consumo de drogas: la primera, se sitúa en Madrid, en mayo de 2000 con la implementación del Dispositivo de Venopunción Asistida en el barrio chabolista de las Barranquillas; la segunda, en Barcelona, desde mayo de 2001 hasta finales de 2004, con el Espacio de Venopunción Asistida del barrio de Can Tunis, considerado un "supermercado de la droga". Muy diferente fue el caso de la ciudad de Bilbao, que instaló la Sala de Consumo Supervisado en noviembre de 2003 en el barrio de San Francisco, tras evidenciarse su necesidad y realizarse un largo trabajo comunitario con todas las partes implicadas (vecinos, policía, comerciantes, usuarios y profesionales) (Ilundain y Markez, 2005, p. 291-293).

A partir de finales de 2003, se extienden por la ciudad de Barcelona. Tras el cierre de la venta de drogas en el barrio de Can Tunis, entre octubre y noviembre de 2003, no se aprovisionó bien el inminente traslado de los consumidores hacia el centro de la ciudad. Sólo se contó con el EVA del SAPS (en octubre de 2003). Tras varias movilizaciones de profesionales y afectados, respalda- dos por varias entidades, se tomarían medidas de lo que comenzaba a ser una situación cruda para los consumidores de drogas. Entre 2004-2005, se abrirían $4 \mathrm{SCH}$ s nuevas en Barcelona y su periferia (Ilundain y Márkez, 2005; Metamorfosis, 2006): durante el verano de 2004, se abre "El local" del barrio de La Mina de la ciudad periférica de Sant Adrià del Besós, donde se trasladarían muchos de los consumidores; en diciembre de 2004, se abre la sala Baluard en el barrio del Raval (cercana al SAPS); en abril de 2005, se instala una unidad móvil-Bus en el barrio de zona Franca, muy cercano a otra zona de venta de drogas; $y$ en julio de 2005, se instala un CAS con EVA en el recinto del hospital de la Vall d'Hebron. Éste acabó trasladándose a una zona contigua del hospital por las fuertes presiones vecinales. $Y$ por último, en 2009, se instaló una SCH en el centro de la ciudad de Lleida. Hoy en día, estas SCHs funcionan con más o menos éxito, pero en todos los casos se consideran estrategias necesarias para reducir los daños del consumo de drogas.

Las SCHs van dirigidas a toda persona que necesite condiciones higiénicas y de seguridad para el consumo. Aunque el perfil de personas que acude es muy heterogéneo, normalmente suelen ser hombres, entre 30-35 ańos, con graves problemas de salud y en exclusión social. Los objetivos de las $\mathrm{SCH}$ s giran en tres ejes: sanitario, social y jurídico-penal (Bertrand, 2005; Delás et al, 2007; Hedrich, 2004; Hunt, 2006):

a) A nivel sanitario, las $\mathrm{SCH}$ s son dispositivos sanitarios donde el usuario de drogas consume sustancias ilegales bajo el control de un profesional dispuesto a actuar en caso de necesidad. Persigue los siguientes objetivos: 1) Que la persona prepare y consuma las sustancias en condiciones higiénicas (lavado de manos, uso de material nuevo e higiénico, etc.); 2) Promover hábitos saludables y educación sanitaria para evitar prácticas de riesgo; 3) Evitar enfermedades infectocontagiosas (VIH, hepatitis, infeccio- 
nes bacteriológicas, etc.); 4) Promover un lugar seguro a las reacciones de los efectos negativos de las sustancias; y 5) Promover la atención sanitaria y tratamiento a los usuarios que lo necesiten.

b) A nivel social, las $\mathrm{SCH}$ dirigen sus objetivos para: 1) Reducir la conflictividad comunitaria, al reducirse las prácticas del consumo en la vía pública.; 2) Mejorar la relación con el vecindario y las fuerzas de seguridad; 3) Potenciar la integración social de los consumidores en situación de exclusión social, promoviendo la vinculación a los servicios sociosanitarios; y 4) Promover la privacidad de la persona consumidora.

c) A nivel jurídico-penal, consumir en la calle está prohibido; supone una multa administrativa, por lo que consumir en un espacio permitido, reduce la criminalización de los consumidores. Por lo tanto, los objetivos de las SCHs son: 1) Disminuir las infracciones por consumir en la calle; y 2) Disminuir las consecuencias negativas de la intervención policial.

A pesar de ser beneficiosas para la sociedad, siguen creando polémica y desconfianza. Siempre existen reticencias por parte de los vecinos, produciéndose el síndrome NIMBY (not in my back yard), "no en mi patio trasero". Su discurso se basa en consignas de rechazo y exclusión, apoyándose, eso sí, en aspectos sociodemográficos de su barrio y en el temor a la peligrosidad social o a la devaluación inmobiliaria (Ilundain y Markez, 2005, p. 294).

Las SCHs se pueden clasificar dependiendo de una serie de criterios. Nos basaremos en tres:

1) Según ubicación podemos encontrar SCHs: a) cerca de los lugares donde se consume: un buen ejemplo es Can Tunis. El EVA se instaló muy cerca de las casas dónde se vendían drogas; b) Dentro de los CRD: la Sala Baluard, La Mina y el SAPS, que se ubican cerca de zonas residenciales por las que merodean los consumidores de drogas; c) Dentro de un hospital: en la Vall d'Hebron de Barcelona.
2) Según oficialidad, existen salas no-oficiales, semi-oficiales y oficiales. Las primeras $\mathrm{SCH}$ s surgieron de forma no-oficial o semioficial, durante los años 60-70, en Reino Unido, en los años 70, en Holanda, y en los años 80, en Suiza (Hedrich, 2004, p. 15; Hunt, 2006, p. 3). Más tarde algunas de estas $\mathrm{SCH}$ se oficializaron. En España, por ejemplo, el EVA de Can Tunis se implementó de manera semioficial con una carpa, y más tarde se habilitó oficialmente en un autobús (Anoro, Ilundain, Santiesteban, 2003).

3) Según la vía de consumo, en las $\mathrm{SCH}$ se pueden consumir sustancias ilegales (cocaína y heroína) por vía esnifada, vía inyectada y vía pulmonar. Pero no todas ofrecen plazas para los diferentes consumos. En principio, las SCHs nacieron para el consumo por vía inyectada, y no se consideró la provisión de plazas para el consumo inhalado. En cualquier caso, todas disponen de plazas individuales para la preparación y consumo y, en concreto, las SCHs de consumo inhalado disponen de extractores para evitar la concentración de humos.

\section{3) El estudio de la cotidianidad: usuarios y profesionales interaccionando}

Para el estudio de la cotidianidad en el EVA requiere sumergirse en un contexto donde usuarios y profesionales intercambian significados, previamente elaborados, a partir de la interpretación de la realidad. Cada uno de los participantes adoptará una función en el contexto de la interacción, modulándose una realidad separada del exterior de la institución: "la estructura social, el orden simbólico, etc. existen, pero lo decisivo de la "vida social" no está en dicha estructura sino en las (re)presentaciones y prácticas que ejercen los sujetos" (Menéndez, 
262 RAFA CluA

2000 , p. 81), es decir, "los aspectos estructurales, como la "cultura", "sistemas", "estratificaciones" y "papeles" sociales, establecen las condiciones para la acción de dichas unidades, pero no la determinan” (Blumer, 1982, p. 66).

El encuentro entre los "equipos": negociación de la norma

En el contexto de la interacción, entendemos como equipo a las personas que se constituyen como grupo para representar un rol en busca de unos intereses comunes; en nuestro caso, hablamos de los usuarios y los profesionales del EVA. Los profesionales de SAPS trabajan bajo un mismo prisma de actuación, llevando a cabo una serie de programas. Para ello, cuentan con unas pautas y normas que regulan el orden en establecimiento, dirigidas tanto a los usuarios como a los profesionales. Por ejemplo, queda terminantemente prohibido consumir cualquier sustancia en las diferentes áreas del SAPS (excepto en el EVA). Tampoco está permitido consumir en la entrada al centro, las escaleras ni el pasillo que accede al espacio destinado al PIJ. No se permite vender drogas, ni hacer uso de la violencia, ni verbal ni física. Cualquiera de estas acciones puede ser motivo de expulsión. En muchas ocasiones, en las reuniones de equipo, los profesionales negocian la forma de actuar ante los usuarios. A través de los encuentros, se irá definiendo las acciones entre los "equipos".

Entre los usuarios del SAPS, existen intereses comunes, aunque no siempre es así. En el caso que no coincidan las decisiones del grupo para crear y/o fomentar unas normas y valores sociales, se producirán tensiones entre los consumidores y en el contexto de la interacción.

El SAPS es el territorio del equipo emergente, los profesionales. Éstos diseñan unas normas con el objetivo de controlar al "equipo visitante", los usuarios del SAPS. Ante el diseño de normas, los usuarios pueden "escoger entre adherirse a las reglas o disimular sus infracciones, y que si no hace ninguna de las dos cosas, se le arrancará de su situación y se le obligará a pagar las consecuencias" (Goffman, 1979, p. 118). La suma de encuentros y la repetición de los actos pautados, creará un código de normas. Así, profesionales y usuarios del EVA construyen una realidad, donde los roles se regulan a través de las normas edificadas en la virtualidad de la interacción.

\section{El uso del EVA: modificación de una ceremonia}

Acudir a un EVA, supone realizar la práctica del consumo endovenoso ante profesionales, habitualmente enfermeros/as. Los consumidores llevan consigo un bagaje y una larga experiencia, y conocen las diferentes fases del acto de consumir drogas: preparación de la dosis, búsqueda del lugar de inoculación de la sustancia en el cuerpo, sentir los efectos de la sustancia y desechar el material utilizado. El hecho de exponer sus pautas de actuación ante profesionales, provoca un "encuentro" donde el profesional "negocia” las normas del EVA.

Los usuarios que acuden al EVA ya han realizado el consumo inyectado en su casa (piso/ casa okupa, etc.) o lugares no autorizados (portales, plazas, etc.). Desde el EVA, trazan un nuevo "itinerario" en su carrera moral (Goffman, 1994, p. 133), pasando por diferentes etapas: antes de acudir al EVA, es considerado "yonqui", al usar el EVA, es considerado "usuario" y en el momento que deje de acudir, será “ex-usuario”. Mientras, el personal tendrá el derecho de recoger sus datos personales, esto "permite manejarlo con más provecho para él y 
menos riesgos para los demás" (Id., Ibidem, p. 162). A partir de aquí, los usuarios han de asumir un compromiso. De esta manera, el EVA acaba constituyéndose como un espacio para institucionalizar el consumo de drogas ilegales. En este caso, el usuario que acude al EVA entra en un entramado de normas, cambiando sus pautas de consumo, que "no es a menudo más que un cambio en los símbolos ceremoniales, que deja intacta la estructura básica de la organización y el control social" (Szasz, 1990, p. 189). Se produce un cambio ceremonial: de un "ritual religioso" a un "ritual médico".

Los efectos de la institucionalización: el "yonqui" se torna asistible

La intencionalidad de los usuarios es reproducir su ritual habitual, sin tener en cuenta que "se hallará limitado en tanto permanezca ignorante de la naturaleza de los caminos ocultos que la naturaleza estipula” (Hall, 1981, p. 132). Deberá asumir las pautas marcadas por los profesionales. Éstos irán cediendo terreno, en la medida que reformulen y comprendan las diferentes representaciones de los usuarios, si son necesarias. El consenso apaciguará la hostilidad que supone la imposición de normas. Llegará un momento en que los roles de ambos equipos quedan equilibrados, con unos objetivos comunes.

El "antiguo yonqui", ahora usuario del EVA, mantendrá "contactos mixtos" (Goffman, 2001, p. 23) con los profesionales, y continuará teniendo contacto con sus iguales. Puede que en el proceso de negociación de las nuevas pautas - que va integrando con los profesionales junto con la no-identificación de los usuarios del EVA -, los usuarios deseen un alejamiento del grupo social que lo categoriza. El usuario pretenderá mantener cierta naturalidad, sobre todo cuando se halle ante un "normal": "el sujeto tendrá una versión de sí mismo que desea mantener ante las personas presentes, y en parte esto entrañará lo que comunica mediante su conducta corriente" (Goffman, 1979, p. 276).

El consumidor de drogas asume una nueva identidad, replanteándose cambios en su modo de vida. Asume que tiene un problema y pide ayuda a las personas que le supervisan en el EVA. Pasa de ser un "yonqui" a ser un usuario, cambiando su credo; se vuelve "asistible".

\section{4) Exclusión social en las ciudades}

Los consumidores de drogas que solicitan ayuda en los CRDs, son personas que están en riesgo de exclusión social, dentro de "un proceso de segregación social” (Tezanos, 2001, p. 140), fuera de las "oportunidades vitales" de ciudadanía y considerados no-ciudadanos, estatus al que se llega por diferentes vías. Existen múltiples conceptos relacionados con la noción de exclusión social. En nuestro caso, nos centraremos en los conceptos que se relacionan con las vivencias sociales: la "marginación" y “desviación” (Idem, Ibidem, p. 141).

\section{Procesos sociales de la exclusión social: marginación $y$ desviación}

El concepto "marginación” puede definirse como: "un apartamiento o alejamiento del núcleo central de una sociedad o grupo, que no es de carácter voluntario sino forzado" (Id., Ibidem, p. 141). La mayoría de usuarios del SAPS no tienen vivienda fija, llevan largos procesos de problemas de salud relacionados con las drogas y vidas itinerantes con desapego familiar o pocas 
264 RAFA CluA

redes sociales. En consecuencia, son considerados "clase marginada": "categoría de personas que está por debajo de las clases, fuera de toda jerarquía, sin oportunidad ni siquiera necesidad de ser readmitida en la sociedad organizada" (Bauman, 1999, p. 103). En parte, esta exclusión está causada por los efectos secundarios del Estado del Bienestar, que pretende garantizar la eliminación de las desigualdades, bajo supervisión del Estado (Id., Ibidem). Supone proveer al pueblo de trabajo, salud y educación. Curiosamente sólo se beneficia de este "bienestar" la parte de la sociedad que forma parte del mundo laboral, los que están asistidos y protegidos socialmente. Mientras, aumentan las colas del paro, los indocumentados, los desprotegidos, los no-ciudadanos.

Otro proceso de la exclusión social, trabajado por Larrauri (2000), es la "desviación" que surge como consecuencia reaccionaria al capitalismo: oposición a las nuevas pautas y a las formas autoritarias de vida. Estar fuera de las nuevas pautas obliga a las personas a quedar sumergidas en la cultura dominante. Establecida la norma, se produce una diferenciación entre la perspectiva normal y la desviada. Bajo la perspectiva desviada, la persona representa su rol, no negociado, no aceptado, produciéndose la divergencia llamada "estigma". A la persona se le asignan unos atributos desacreditadores e inventará mecanismos para no levantar sospechas: el encubrimiento y el enmascaramiento (Goffman, 2001, p. 91-125), mecanismos muy utilizados por los consumidores de drogas.

Ambos procesos sociales conducen a la persona a la exclusión social. Parafraseando a Bauman (1999, p. 113-116) cada vez es más difícil alcanzar los hábitos del consumismo. Supone un estilo de vida inalcanzable para las clases marginadas seducidas. El consumismo en ciertas personas, se traduce en consumo de drogas. El precio a pagar es la pobreza. Otros intentan adhe- rirse al mundo laboral, pero la mayoría de los miembros de estas infraclases no tienen estudios especializados y no pueden optar a sueldos que sostengan la supervivencia. En consecuencia, los consumidores de drogas optan por "buscarse la vida", en el argot, a buscar maneras alternativas para cubrir sus necesidades. En ocasiones, supone exponerse a violar la ley: venta de drogas, hurtos o robos, y/o realizar trabajos no reglados. En términos de Wacquant, "se ha producido la modernización de la miseria: el ascenso de un nuevo régimen de desigualdad y marginalidad urbana" (Wacquant, 2001, p. 168). Esta idea, muy ligada a Bauman (1999), refiere que el Estado de Bienestar decide cómo, cuándo y dónde se puede entrar en el mundo laboral o quedarse fuera. Mientras, han aumentado las solicitudes de prestaciones sociales al Estado, perdiéndose el valor del trabajo. Las bolsas de miseria irán recogiéndose desde los servicios cedidos por el Estado a los gestores de la "neobeneficiencia" (ONGs, empresas privadas, fundaciones, etc.). El Estado externaliza los dispositivos destinados a las personas que no son rentables a empresas que funcionan dentro de lo "público", dividiendo los servicios en los dirigidos a los ciudadanos afines a la lógica capitalista, y los dirigidos a los marginados. Uno de estos servicios son las $\mathrm{SCH}$ s, como lo son las comunidades terapéuticas, comedores sociales, albergues, entre otros.

\section{¿Son los EVA no-lugares?}

No podemos responderlo de manera inmediata. Según Marc Augé (2000), un no-lugar es un espacio con ausencia de lugar, una negación. Posiblemente, si no tiene utilidad o no se aprecia; y puede ser considerado como innecesario. En cambio, los profesionales tienen en este espacio unos objetivos dirigidos a los usuarios de 
drogas. En este lugar, "despojado de las expresiones simbólicas de la identidad, las relaciones y la historia” (Bauman, 2003, p. 111) de los consumidores, se aceptará por un periodo corto de tiempo, unos patrones de comportamiento que se repetirán en cada encuentro.

Viajar a estos espacios es como estar en otra parte. Por él diariamente, pasan muchas personas/ usuarios y sus "experiencias nos enseñan inconscientemente que el espacio comunica cosas" (Hall, 1981, p. 176), existiendo múltiples significaciones de este. En el espacio, se toman decisiones; acudir a él, significa un cambio en el usuario. Aquí, dispone de un lugar donde expresar sus sentimientos, conversar con los "parroquianos" y hablar de los "ausentes". Es un lugar donde maldecir, excusarse, quejarse, donde desprenderse del peso arrastrado a lo largo del día.

Estos lugares comienzan a "generar historia”, pero para muchos no suponen nada, los desconocen, los ignoran: "podríamos decir que son lugares sobrantes que quedan después de que se ha llevado a cabo la tarea de estructuración de los espacios que realmente importan” (Bauman, 2003, p. 112). Los EVAs son no-lugares y lugares. Para unos no existen, no tienen uso, están vacíos, sirven para apartar a las no-personas. Para otros, suponen un lugar de trabajo o una "taberna clandestina" reconvertida en "iglesia", un "templo secreto" para la celebración de un ritual (Szasz, 1990, p. 59).

\section{3) Métodos de investigación}

Se trata de una investigación cualitativa de tipo descriptivo-interpretativo sobre el caso del EVA del SAPS. Bajo la triada "sujeto-droga-contexto”, propuesta por Zinberg en 1984 (Díaz, 2000, p. 31), nos hemos centrado en el contexto, evitando el sesgo que produciría la focalización en todos sus vértices. De este modo, y siguiendo los consejos de Edwards y Arif (1981), hemos analizado los roles y las experiencias entre los profesionales y los usuarios, unidades relevantes en cualquier estudio sociocultural relacionado con las drogodependencias. Dentro de este contexto, la función del etnógrafo ha sido la de situarse entre dos bandos para mediar/traducir el lenguaje cultural producido en el EVA.

Según la variable "tiempo", se trata una investigación transversal. Se describe lo que ha sucedido en un mismo periodo de tiempo, de febrero a junio de 2010, acudiendo alrededor de 30 veces al campo de estudio.

La estrategia de investigación ha sido el trabajo de campo. Los resultados de éste no nos debe conducir a una generalización, pues "el análisis cultural es intrínsicamente incompleto" y cuanto más queramos ahondar menos completo es (Geertz, 2003, p. 39). Por lo que, la suma de casos, en posteriores investigaciones, fortalecerá los resultados de este estudio.

\section{1) Preguntas previas a la investigación}

La investigación comenzó a finales de febrero de 2010. Previamente, se plantearon las hipótesis y supuestos, preguntas necesarias para dar respuestas a los objetivos de esta etnografía. Las principales hipótesis son las siguientes:

a) La desritualización del consumo de drogas por vía parenteral lleva a los usuarios a replantearse cambios en la vida. Se entiende por "desritualización", al paso de consumir en situaciones desfavorecidas (en la calle, sin atención sanitaria, expuesto a daños sociales, etc.) a consumir dentro de una institución sociosanitaria. Acudir a un EVA es un proceso en el que el consumo se convierte en una práctica protocolizada. Inyectarse en este lugar, despojado de 
266 | RAFA CluA

los elementos culturales del consumo marginal de drogas, puede producir cambios en el modo de vida del consumidor. Quizás, decida emprender unos hábitos de consumo más saludables y/o solicitar otro tipo de intervención.

b) El uso del EVA ha desestigmatizado, en cierto grado, a los usuarios de drogas por vía parenteral (UDVP) por no exponerse al desenmascaramiento de su situación. Utilizar el EVA posibilita el manejo de la información a los UDVP, siendo una estrategia para encubrir o enmascarar su condición de consumidor de drogas, y que otras personas no sepan nada acerca de su biografía. Además, el uso del EVA reduce la exposición de la práctica de la inyección ante un público vecinal, policial y/o familiar.

Además, se plantearon los siguientes supuestos para apoyar las hipótesis principales: a) Los UDVP dan el paso del consumo en lugares públicos o familiares al EVAs porque han padecido daños sociales (estigmatización, presión policial, etc.) y sanitarios (sobredosis, contagio de enfermedades infectocontagiosas, etc.); b) El paso del consumo en lugares públicos o familiares al EVAs (consumo institucionalizado) es percibido por los usuarios como una mejora en su calidad de vida; c) Los UDVP consumen en el EVA porque han vivido experiencias relacionadas con la muerte y reconocen este espacio como un lugar seguro; d) Los UDVP que usan el EVA solicitan otras intervenciones y/o tratamientos para mejorar su calidad de vida; y e) Los UDVP usan el EVA por una cierta satisfacción en las intervenciones de sus profesionales.

\section{2) Llegar, observar, recoger y analizar}

A mediados de febrero de 2010, fui presentado al SAPS y pude exponer los objetivos de la investigación. Iniciada la investigación, se me brindó la oportunidad de entrar en el EVA. Allí comencé a conocer cómo los usuarios y profesionales interactúan y modulan el intercambio de representaciones ante el uso del espacio. A partir de aquí, mi observación se alternó por las diferentes áreas del centro. Acudía dos días a la semana, de 19 a 23 h., y elegía dónde situarme para comenzar la observación: el Club, PIJ, la enfermería, el EVA y las escaleras. Desde la zona de entrada, pude comenzar a interactuar con los usuarios que accedían al centro o que pedían material para llevar fuera de éste. Durante mi instancia en el SAPS, utilicé una libreta de pequeñas dimensiones para tomar notas que luego se traspasarían a un diario de campo. En éste, se redactó la mayor información posible. Posteriormente, releí y analicé los datos poniendo gran atención en las diferentes variables planteadas en las hipótesis y supuestos generales.

Durante el trabajo de campo, fui captando a los diferentes profesionales para ser entrevistados. En el caso de los usuarios, no pudo ser siempre así y tuve que utilizar otros métodos, pues siempre tenían alguna tarea que hacer (entrar en la enfermería, ducharse, utilizar el EVA, etc.). Tres de los usuarios se entrevistaron dentro del centro, en diferentes momentos: en el pasillo que accede al PIJ, el Club o dentro del EVA, mientras el usuario preparaba la dosis para inyectarse. No eran suficientes y tuve que buscar otra estrategia. Me plantearon acudir los martes de 15 a 17:30 al programa Reco.Je: programa que consiste en captar a 5 usuarios, bajo sorteo, para realizar la búsqueda y recogida de jeringuillas desechadas en la vía publica. Este programa lo gestionaba uno de los educadores del SAPS, persona que ayudó a proponer las entrevistas a los diferentes usuarios. Algunas comenzaban a realizarse en alguna de las paradas del recorrido del Reco.Je y se acababan a la vuelta al SAPS. Finalmente, la muestra se compuso de ocho usuarios del EVA, según criterios afines 
a los porcentajes de sexo, edad, procedencia y sustancia de consumo del Informe 2008 del SAPS (Díaz et al., 2009), y tres profesionales.

Las entrevistas semiestructuradas se diseñaron según la persona entrevistada. A los "Usuarios" se les realizó preguntas cerradas sobre datos personales, sociodemográficos y socioeconómicos, y preguntas abiertas sobre: 1) Estado de salud actual, consumo de drogas e itinerarios terapéuticos para el abordaje del consumo de drogas; 2) Daños sociales y sanitarios padecidos antes del uso del EVA (incluye daños que padecen en la actualidad): detenciones, sobredosis, enfermedades, etc.; 3) Sobre el uso del EVA: por qué lo usan, qué usan y qué motivaciones tienen; 4) Comparación del consumo en la calle con el consumo en un EVA; 5) Uso del recurso (asistencia social, tratamientos, café-calor, etc.); 6) Opinión y satisfacción del SAPS y sus profesionales; y 7) Expectativas de vida. A los "Profesionales", se les realizó preguntas cerradas, sobre datos sociodemográficos y datos profesionales, y preguntas abiertas, sobre: 1) La cotidianidad laboral: interacción con los usuarios y los profesionales; 2) Sobre su percepción del uso del EVA: usos, motivaciones y cambios de los usuarios, y el su rol profesional en el EVA; 3) Sobre su opinión del centro y los diferentes programas que se ofrecen; y 4) Sobre la satisfacción del rol profesional.

En resumen, se observó que los usuarios no tenían domicilio fijo, viviendo muchos de ellos en la calle; todos tenían documentación, tarjeta sanitaria y estudios básicos, y ninguno de ellos trabajaba. Los ingresos que recibían, provenían de prestaciones sociales y colaboraciones en el programa comunitario de recogida de jeringuillas (Reco.Je) del SAPS, entre otros. Los ingresos no reglados provenían de pequeños trapicheos, venta de chatarra y hurtos. A nivel de salud, todos hacían referencia a las patologías infectocontagiosas. Todos llevaban una larga evolución de consumo, habiendo realizando diversos tratamientos para la drogodependencia. En el caso de los profesionales, se entrevistó a una enfermera y un educador, veteranos en el SAPS y con larga trayectoria y formación en el campo de las drogodependencias, y a un enfermero novel, con poca trayectoria y formación en le campo de las drogodependencias.

Durante mi estancia en el SAPS fui recopilando diferentes documentos interesantes para ser analizados: Informe de la actividad durante el 2008 (Díaz et al., 2009), memorias de la actividad del EVA, normas de funcionamiento y consentimiento informado del EVA, normas de los trabajadores dentro del SAPS, y protocolos de actuación. Para completar la información, diseñé un mapa-callejero de los principales centros sociosanitarios del barrio del Raval. Sirvió para ubicar los diferentes centros nombrados a lo largo del desarrollo etnográfico. Para ilustrar las explicaciones, se tomaron fotos de los diferentes espacios del SAPS.

Para el tratamiento de los datos se utilizaron dos tipos de análisis dependiendo de la herramienta de recogida de datos. Para los documentos, anteriormente comentados, se realizó un análisis documental. Sobre todo, con el "Informe SAPS 2008" tuve una visión general del centro, extrayendo las diferentes estadísticas sobre el desarrollo de los programas llevados a cabo en el transcurso del año 2008, teniendo una primera fotografía de las características de los usuarios que acuden al SAPS, en concreto de los que utilizaban el EVA. Pude extraer cuáles son las normas y pautas de funcionamiento de los diferentes programas del SAPS del resto de documentos, muy interesante para conocer si estas normas y pautas de funcionamiento guardaban consonancia con la información recogida en el trabajo de campo. Estos datos se "cruzaron" con las informaciones extraídas del análisis de contenido. 
El análisis de contenido se utilizó para el diario de campo y las entrevistas semiestructuradas. A partir de la lectura, se creó una sistematización de los datos mediante "cajas de información". Del diario se extrajeron párrafos relacionados con las variables de las hipótesis y los supuestos. Se clasificó los párrafos por temas, permitiendo captar los más recurrentes y necesarios para la descripción de la cotidianidad del fenómeno estudiado. Las entrevistas semiestructuradas se transcribieron y vaciaron, delimitando los temas y aspectos relacionados con los objetivos y variables de la investigación. Los datos vaciados se "cruzaron" con los datos del diario de campo. El análisis de los diferentes temas se desarrolló ofreciendo resultados y respondiendo a las hipótesis y supuestos generales.

\section{Concluyendo: los aportes de la antropología en el estudio de las SCHs}

¿Cuáles son los aportes desde una perspectiva antropológica? En primer lugar, los enfoques teóricos nos acercan a una contextualización ideal para conocer y cuestionar nuestras políticas de drogas actuales. De este modo, conoceremos mejor los procesos y la evolución de la intervención en drogas, seduciéndonos a ponerla en crisis y a promover cambios de mejora. Por otro lado, poder relacionar el fenómeno de las drogas con las teorías sociales, que analizan el contexto social, económico y político, nos ayuda a escapar de la idea que la génesis de los efectos negativos del consumo de drogas son los consumidores y las drogas. Escapa de lo moral, vuelve el análisis más complejo, pero los resultados responden a la realidad, evitando sesgos de carácter prohibicionista. En segundo lugar, la etnografía es una labor que trabaja a nivel microsocial, permitiéndonos recoger datos in situ. Haber realizado la investigación desde el enfoque del interaccionismo simbólico, nos ha facilitado el conocimiento de la construcción social del uso del EVA entre los grupos sociales estudiados. Mediante el uso de diferentes técnicas de recogida de datos y de análisis, ha sido posible responder a nuestras preguntas iniciales, obteniendo resultados que desde otras perspectivas no serían posibles. En cualquier caso, todo aporte es útil y complementario para seguir avanzando en la intervención en drogas desde las SCHs.

La mayoría de estudios demuestran los efectos positivos del uso de las $\mathrm{SCH}$, en nuestro caso, hemos podido corroborarlo: el EVA reduce daños sanitarios, evitando muertes por sobredosis, infecciones y reinfecciones por el uso compartido de material para la preparación e inyección de drogas. Los usuarios adoptan pautas higiénicas y mejoran la praxis de la venopunción. El EVA reduce daños sociales evitando la exposición de los consumidores de drogas ante vecinos, transeúntes, familiares y allegados. El EVA reduce daños jurídicos. Acudir al EVA evita que los consumidores expongan sus prácticas de consumo en medio de la vía pública. Éstas pueden ser motivo de una falta administrativa si los consumidores son descubiertos por la policía. En consecuencia, los consumidores de drogas mejoran su calidad de vida, mejorando notablemente el orden público.

Respondiendo a las preguntas iniciales y supuestos de la investigación, extraemos las siguientes conclusiones:

a) Los consumidores de drogas que acuden a un EVA trazan una nueva trayectoria en su "carrera moral". Esta comienza en el momento que pone un pie en las escaleras que dan acceso al acceso al SAPS. Éstas no sólo son una parte del trayecto de los usuarios. En ocasiones, se transforma en un lugar para consumir - aun- 
que no está permitido por los profesionales del centro -, sobre todo cuando existen aglomeraciones en el EVA, pues sólo tiene plazas para 2 personas. Digamos que es un lugar intermedio en la "carrera moral" del consumidor. Desde la escalera, se comienza a barajar entre pasar a ser un usuario del centro sociosanitario o a correr el riesgo de consumir en la calle y ser considerado un delincuente. Una vez dentro de la institución y de transformarse en asiduo, el consumidor de drogas atraviesa diferentes fases y aumenta el nivel de participación dentro de la institución: pasa a ser considerado usuario.

b) En el EVA se produce un cambio de ritualización del consumo de drogas. En el EVA, el "ritual yonqui" mantiene sus objetivos básicos y pautas, pero sufre una cierta modificación hacia un "ritual médico". Tras la desritualización del consumo, el usuario entra en crisis. No acepta ser consumidor de drogas, ni tampoco usuario. Puede llegar a rechazar a sus iguales. Acepta un acercamiento a los "normales", los profesionales, para que le ayuden a salir del mundo en el que viven. El EVA es uno de los pocos lugares donde los usuarios están en contacto con el mundo sanitario. Muchos no acuden a ningún servicio normalizado, por lo que El EVA supone un trampolín hacia posibles intervenciones para mejorar su salud.

c) El EVA es un espacio limitado. Pese a ser un lugar bien aprovechado, supone un lugar pequeño, con pocas plazas, con poco tiempo para consumir (sólo 20 minutos), que sólo permite el consumo por vía inyectada, con una franja horaria reducida y una infraestructura insuficiente. Tampoco existe un lugar donde los usuarios puedan repartirse la dosis si la han comprado juntos. Esto provoca que muchos lo hagan en la escalera u otros lugares del centro.

d) Los consumidores de drogas continúan en una situación de exclusión social. La red asistencial en drogodependencias ha evolu- cionado mucho desde sus inicios cuando el consumidor de drogas era considerado un "delincuente-enfermo". Tras tres décadas, el modelo de intervención ha cambiado hacia un enfoque sociocultural del "problema" y los centros de atención a las drogodependencias continúan luchando en diferentes direcciones para paliar, erradicar o sostener el consumo de drogas. Pero existe un mal mayor, la marginalidad, en parte creada por el prohibicionismo que impide un cambio sustancial de mejora en los consumidores de drogas.

Demostrados los efectos positivos de las $\mathrm{SCH}$, cabe dar un paso más en la intervención en drogodependencias. Propongo que las políticas de drogas deben revisarse para ofrecer mejores recursos que los actuales. Los CRDs y la red socio sanitaria de la ciudad de Barcelona deben coordinarse, para ofrecer alternativas y cubrir las necesidades básicas de los consumidores, así como movilizarse para promover nuevos desafíos desde el prisma de la reducción de daños. Como pronto, deben mejorar las instalaciones de las SCHs, para que exista la posibilidad de consumir por vía intravenosa, pulmonar e intranasal. Resumiendo, las SCHs necesitan ampliarse, diversificarse y ajustarse a las necesidades de los consumidores de drogas y de los profesionales y, porqué no, de los vecinos, transeúntes y policía.

\section{No ritmo do bombeio: teoria e métodos para o estudo antropológico em um espaço de venopunção assistida em Barcelona}

resumo Este artigo aborda, através de um plano teórico-metodológico, um estudo realizado no Espaço de Venopunção Assistida (EVA) do Servei d'Atenció i Prevenció Socio Sanitària (SAPS) de Creu Roja, em Barcelona. Um EVA é um lugar onde se consume drogas por via intravenosa sob a supervi- 
são de um profissional. A pesquisa se contextualizou pela perspectiva histórica da intervenção de drogas na Espanha, investigando o fenômeno das salas de consumo higiênico $(\mathrm{SCH})$, sob o enfoque do interacionismo simbólico e das teorias atuais acerca da exclusão social. No trabalho de campo, utilizou-se diferentes técnicas de coleta de dados e análises com o objetivo de traçar conclusôes e propostas para melhorar a intervençáo de drogas nas SCHs. Esta pesquisa constitui-se como uma nova abordagem para o estudo das $\mathrm{SCH}$, complementando os resultados obtidos por outras perspectivas.

palavras-chave Salas de consumo higiênico. Interacionismo simbólico. Drogas. Exclusão social. Métodos de pesquisa.

\section{Notas}

1. Actualmente es enfermero en el Centro de Atención y Seguimiento a las Drogodependencias del Centro Penitenciario Brians 1 (Sant Esteve de Sesrovires, Barcelona). Enviar correspondencia a: cluag@msn.com

\section{Referências bibliográficas}

\section{AGÈNCIA DE SALUT PÚBLICA DE BARCELONA.}

Programa dispensación metadona para drogodependientes marginales. Barcelona: ASPB, 2004.

ANORO, M., ILUNDAIN, E., SANTISTEBAN, O. Barcelona's safer injection facility - EVA: A harm reduction program lacking oficial support. The Journal of Drug Issues, Florida, p. 689-712, 2003.

AUGÉ, M. Los no lugares. Espacios del anonimato. Una antropología de la sobremodernidad. Barcelona: Gedisa, 2000 [1992].

BAUMAN, Z. Trabajo, consumismo y nuevos pobres. Barcelona: Gedisa, 1999 [1998].

. Modernidad liquida. Buenos Aires: F.C.E, 2003 [2000].

BERTRAND, B. On peut franchir le pas, faire un essai. In: (Org). Structures d'accueil avec possibilité de consommer à moindre risque des drogues. Paris: Association LUDIC, 2005.
BLUMER, H. El Interaccionismo simbólico: perspectiva y método. Barcelona: Hora, 1982 [1969].

CLUA, R. Programa de Intercambio de Jeringuillas: dos años de experiencia en CP Brians 1. In: CLAT Virtual 2, 2008.

DELÁS, J. et al. (Org.) Atención sanitaria en zonas urbanas socialmente deprimidas. Barcelona: El Ciervo 96, 2007.

DÍAZ, A. El estudio de las drogas en distintas sociedades. Problemas metodológicos. Contextos, sujetos y drogas: un manual sobre drogodependencias. Barcelona: Grup Igia, p. 31-42, 2000.

DÍAZ, A., BARRUTI, M., DONCEL, C. Les línees de l'exit? Estudi sobre la naturalesa i l'extensió del consum de cocaïna a Barcelona. Barcelona: Ajuntament de Barcelona, 1992.

DÍAZ, O. et al. Informe SAPS: 2008 Servei d'Atenció i Prevenció Sòcio Sanitària. Barcelona: Creu Roja, 2009.

EDWARDS, G. y ARIF, A. Los problemas de la droga en el contexto sociocultural. Una base para formulación de politicas y planificación de programas. Ginebra: OMS, 1981.

FUNES, J. y ROMANÍ, O. Dejar la heroina: vivencias, contenidos y circunstancias de los procesos de recuperación. Madrid: Cruz Roja Española, Dirección General de Acción Social, 1985.

GAMELLA, J. F. Heroína en España, 1977-1996. Balance de una crisis de drogas. Claves de Razón Práctica, Madrid, n. 72, p. 20-30, 1997.

GEERTZ, C. La interpretación de las culturas. Barcelona: Gedisa, 2003 [1973].

GENERALITAT DE CATALUNYA (Gencat eds.) La qualitat de vida dels ususaris dels programa de metadona. Barcelona: Institut per a la promoció social i de la salut. Departament de benestar i Família, 2002.

GOFFMAN, E. La presentación de la persona en la vida cotidiana. Buenos Aires: Amorrortu, 1993 [1959].

Internados. Ensayos sobre la situación social de los enfermos mentales. Buenos aires: Amorrortu, 1994 [1961].

Relaciones en público: microestudios del orden público. Madrid: Alianza, 1979 [1971].

Estigma. La identidad deteriorada. Buenos Aires: Amorrortu, 2001 [1963].

GUASCH, O. Riesgo y cultura. Determinantes culturales en la definición médica de los grupos de riesgo ante el SIDA. Quaderns d'Antropologia, núm. especial Maig, p. 55-60, 1992.

HALL, E. T. El lenguaje silencioso. Madrid: Alianza, 1981 [1959]. 
HEDRICH, D. European report on drug consumption rooms. Lisbon: European Monitoring Centre for Drugs and Drug Addiction, 2004.

HUNT, N. The evaluation literature on drug consumption rooms. Independent Working Group on Drug Consumption Rooms Paper B. York: Joseph Rowntree Foundation, 2006.

ILUNDAIN, E. y MARKEZ, I. Salas de consumo: entre innovación y mal menor en políticas de drogas. Adicciones, v. 17, n. 2, p. 287-297, 2005.

IRAURGI, I. Reducción de daños y riesgos: lecciones aprendidas y retos futuros. In: Laespada, M. y Iraurgi, I (Org.) Reducción de daños. Lo aprendido de la heroina. Bilbao: Instituto Deusto de drogodependencias, p. 183- 223, 2009.

LARRAURI, E. La herencia de la criminología critica. Madrid: S.XXI, 2000 [1991].

MAGRÍ, N. Las drogas un problema social y sanitario. Epistemología y praxis. En: Arana, X. y Márkez, I. (Org.) Los agentes sociales ante las drogas. Madrid: Dykinson, p. 215-228, 1997.

MANZANERA, R. et al. Afrontar los estragos de la heroína: evaluación de diez años de un programa integral en Barcelona. Gaceta Sanitaria, Barcelona, v. 14, n.1, p. 58-66, 2000.

MENÉNDEZ, E. L. La dimensión antropológica. Contextos, sujetos y drogas: un manual sobre drogodependencias. Barcelona: Grup Igia, p. 79-98, 2000.

METAMORFOSIS (Eds.) Especial sales de consum de Barcelona. ¿¿I per què no? Metamorfosis: Revis- ta de usuaris I usuàries de metadona i qui ho vulgui, Barcelona, n. 26, 2006.

O'HARE P., NEWCOMBE R, MATTHEWS A., BUNING E., DRUCKER E. La reducción de los daños relacionados con las drogas. Barcelona: Grup Igia, 1995 [1992].

PALLARÉS, J. El placer del escorpión. Antropología de la heroina y los yonquis. Lleida, Milenio, 1995.

ROMANÍ, O. Las drogas. Sueños y razones. Barcelona: Ariel, 2004 [1999].

ROMERO, M. et al. Programas de jeringuillas. Adicciones, v. 17, n. 1, p. 257-275, 2005.

SZASZ, T. Drogas y ritual. La persecución ritual de drogas, adictos e inductores. México-Madrid: F.C.E, 1990 [1985].

TEZANOS, J.F. La sociedad dividida. Estructuras de clases $y$ desigualdades en las sociedades tecnológicas. Madrid: Biblioteca Nueva, 2001.

USÓ, J.C. Drogas y cultura de masas (España 1855 1995). Madrid: Taurus, 1995.

WACQUANT, L. Parias urbanos. Buenos Aires: Manantial, 2001 [2001].

\section{Agradecimientos}

A los profesionales y usuarios del SAPS, a los organizadores del Congreso de antropología UAB-USP 2011, y a mis compañeros de la UAB.

autor

\section{Rafa Clua}

Mestre em Antropologia Social e Cultural / UAB

Recebido em 28/11/2011

Aprovado para publicação em 01/10/2012 